\title{
A New Passive Microwave Tool for Operational Forest Fires Detection: A Case Study of Siberia in 2019
}

\author{
Costas A. Varotsos ${ }^{1, *}$, , Vladimir F. Krapivin ${ }^{2}$ and Ferdenant A. Mkrtchyan ${ }^{2}$ \\ 1 Department of Environmental Physics and Meteorology, National and Kapodistrian University of Athens, \\ 10431 Athens, Greece \\ 2 Kotelnikov Institute of Radioengineering and Electronics, Russian Academy of Sciences, 101000 Moscow, \\ Russia; vkrapivin_36@mail.ru (V.F.K.); ferd47@mail.ru (F.A.M.) \\ * Correspondence: covar@phys.uoa.gr; Tel.: +30-210-7276838
}

Received: 16 January 2020; Accepted: 28 February 2020; Published: 5 March 2020

\begin{abstract}
The purpose of this paper is to present a new method for early detection of forest fires, especially in forest zones prone to fires using microwave remote sensing and information-modeling tools. A decision-making system is developed as a tool for operational coupled analysis of modeling results and remote sensing data. The main operating structure of this system has blocks that calculate the moisture of forest canopy, the soil-litter layer, and the forest physical temperature using the observed brightness temperature provided by the flying platform IL-18 equipped with passive microwave radiometers of $1.43,13.3$ and $37.5 \mathrm{GHz}$ frequencies. The hydrological parameters of the forest are assessed with both a developed regional hydrological model and remote sensing observations. The hydrological model allows for the detection of fire-prone zones that are subject to remote sensing when modeling results are corrected and thermal temperatures are evaluated. An approach for the real time forest fires classification via daytime remote sensing observations is proposed. The relative theoretical and experimental results presented here have allowed us to use a new approach to forests monitoring during periods of potential fire. A decision-making algorithm is presented that aims at analyzing data flows from radiometers located on the remote sensing platform to calculate the probability of forest fire occurring in geographical pixels. As case study, the state of forest fires that occurred in Siberia in 2019 using microwave remote sensing measurements conducted by a flying IL-18 laboratory is presented. This remote sensing platform is equipped with optical and microwave tools that allow the optical and microwave images of the observed forest areas. The main operating frequencies of microwave radiometers are 1.43, 13.3 and $37.5 \mathrm{GHz}$. Microwave radiometers provide data on water content in the forest canopy and on litter and physical temperatures. Based on the long-term measurements made in Siberia, the possible improvement of the proposed decision-making system for future relevant studies is discussed in detail. The basic idea of cost-effective monitoring of forested areas consists of a two-stage exploration of fire risk zones. The first monitoring stage is performed using the hydrological model of the study area to identify low moisture areas of the forest canopy and litter. The second stage of monitoring is conducted using the remote sensing platform only in the local fire-dangerous areas in order to more precisely identify the areas prone to fire and to detect and diagnose real burning zones. The developed algorithm allows the calculation of physical temperatures and the detection of temperature anomalies based on measured brightness temperatures. Finally, the spatial distribution of the probability of forest fire occurrence is given as an example of the decision-making system along with a comparison of this distribution with the satellite images provided by the EOSDIS Land data.
\end{abstract}

Keywords: remote sensing; model; forest fire; probability; Siberia; decision making 


\section{Introduction}

Various aspects of forest fire problems have been examined by many authors [1-3]. Forest fires cause significant loss of lives and hundreds of homes, which require significant financial investments to address their impacts. The main importance of existing forest fire hazards is to solve the following three main problems:

- Advance detection of forest areas prone to fires;

- Early detection of a forest zone vulnerable to fire risk and its effective control.

- Knowledge of diagnostic parameters for identifying the boundaries and direction of the fire.

Unfortunately, existing monitoring systems usually observe forest fire when it has already spread to a forest area, damaging the ecosystem and contributing to environmental changes, such as the addition of $\mathrm{CO}_{2}$ to the atmosphere [4-6]. As Jaforzadeh et al. [7] emphasized the role of forest ecosystems in maintaining environmental balance is the most important factor in global sustainable development. As has been shown by many years of observations, the burning of forests creates many scientific and technological problems, which have no universal solution. However, there are several solutions to these problems on a regional scale [1,8-10]. In these cases, environmental and socio-economic factors should be taken into account considering their regional level, including precipitation, forest type, topography, population density, distance between forest and urban areas, socio-economic development level and other anthropogenic variables. As a result, various models, algorithms and decision-making systems are synthesized as forest fire monitoring tools. However, the main goal of these investigations should be to evaluate the probability of a specific forest fire starting [11-13].

There are many indices of forest fires in different countries and regions that focus on the range of forest fire potential. For example, the well-known McArthur Forest Fire Danger Index (FFDI) is primarily used in Australia where the numerical scales vary due to its adaptation to national environmental and socio-economic parameters. The US and Canada have their own fire danger ratings, e.g., the Canadian Fire Weather Index [9,14]. White et al. [13] proposed the White Model for predicting the occurrence of fire on a daily basis according to maximum air temperature, relative air humidity at 9 a.m. and the number of days with a rainfall greater than or equal to $2 \mathrm{~mm} /$ day. The proposed fire risk index has been shown to provide a reliable prognosis of the fire occurrence in eucalyptus plantations. This model is better than many similar models. In practice, all existing forest fire risk indices are based on the available data provided by national or global monitoring systems whose capabilities are identified using big data processing tools [15].

Understanding the relationships between the forest fire probability and environmental factors can help identify areas with a higher risk of forest fires. All factors of the forest fire occurrence are divided into two classes:

- Slowly changed variables such as population density, distance from industrial and human activity zones, tree and soil types, land use strategy, topography; and

- Rapidly changed variables such as air temperature, precipitation, pressure, wind characteristics and relative humidity.

The integrated approach of analysis to forest fire-prone zone research depends on the diversity of all factors affecting the origin and spread of forest fire. The present study was conducted to develop the most comprehensive forest fire zone detection and diagnosis technology based on coupled remote sensing and modeling tools. This paper proposes the structure of a forest fire risk monitoring system, taking into account all factors and estimates of soil moisture content as the main index of fire risk using microwave remote sensing measurements. The proposed information and instrumentation technology for warning, detection and diagnosing forest fires is being implemented in Russian Siberia, where there is a problem of prior identification of zones with high risk of forest fires. Particularly characteristic are the very inaccessible areas of Siberia (about 30\% of the 605.1 million ha), where remote fire zones can only be controlled by remote sensing tools [16]. 
Remote sensing of land surfaces using microwave radiometers is based on the recording of natural or reflected and scattered electromagnetic emissions. The methods of remote sensing include two main classes: active and passive. This study considers only passive radiometric tools that analyze natural (heat) radiation from natural objects including mainly trees and other land covers. The use of passive microwave radiometers located on flying platforms requires remote sensing systems with acceptable spatial resolution which is possible due to effective data processing algorithms [16-19]. Primarily, the microwave radiometers record the brightness temperature, which is a function of various environmental conditions, which in this study includes the types of forests. Acceptable models and algorithms help to convert brightness temperatures into water content and physical temperature characteristics. As noted by Chukhlantsev [19], the problem of microwave remote sensing of vegetation cover requires the study of the attenuation of electromagnetic waves within the vegetation layer.

Microwave remote sensing and optical observations of large Siberian areas under their combined use allows the identification of the fire-prone areas and the burnt forest zone. Radiometers of 1.43 to $37.5 \mathrm{GHz}$ (wavelength $0.8-21 \mathrm{~cm}$ ) contribute to the estimation of moisture content of the forest canopy and litter as well as to the classification of fire zones such as front, back and smoke-free zones made by physical temperature retrieval. Optical sensors help in the preliminary detection of the fire zone $[16,20]$. However, there is a problem associated with huge Siberian areas where forest fires can occur. The use of remote sensing platforms to monitor this site requires significant financial costs. The approach developed in this paper allows for these costs to be reduced.

Massive forest fires in Siberia took place in 2019 in the Irkutsk region, Krasnoyarsk region, Buriatia, Yakutia, Altaiskii Krai and the Far East. According to Russian News Agency TASS quoting the Krasnoyarsk Forest Fire Center, the causes of the forest fires are natural due to 30-degree Celsius heat (86 degrees Fahrenheit), gusts of wind and dry thunderstorms. The largest area burned by forest fires in Siberia was recorded in the Sakha (Yakutia) Republic [21]. About 13.1 million hectares of Siberian forests have been burnt since early 2019, including 4.3 million ha of taiga forest in Siberia(https://www.greenpeace.org/international/press-release/23660/massive-forest-firesin-siberia-is-a-climate-emergency/). According to the information provided by the Russian Federal Forestry Agency (Rosleskhoz) during 2019 all of eastern Russia had been exposed to higher temperatures resulting in numerous forest fires, the extinguishing of which, required significant financial losses. The idea of this paper is to develop a new effective method for the prior detection of fire-prone zones that are subject to specific monitoring conditions when in-situ measurements are impossible in remote areas.

Many authors have developed different versions of models to study the potential of forest fire occurrence probability (FFOP) taking into account the natural and anthropogenic characteristics of the environment [14]. There are cases where FFOP indices contribute to a more effective fire forecast $[3,22]$. In this study, an attempt was made to develop a new method for detecting hazardous forest fire zones with their preliminary localization functions and after detailed evaluation of fire parameters. A decision-making system (DMS) is proposed to be the main tool for detecting and diagnosing areas prone to fires. The DMS is based on remote sensing measurements of moisture content in the forest canopy and litter as well as the search for physical temperature anomalies in forest areas. Passive microwave radiometers of $0.8-21 \mathrm{~cm}$ wavelength are used [16]. A decision-making algorithm is presented that aims to analyze the data flows from devices located on the remote sensing platform to calculate the probability of forest fire occurring in the pixels.

\section{Materials and Methods}

\subsection{Remote Sensing Platform}

Varotsos and Krapivin [15] have developed an instrumental information-modeling method that enables decision making when available data are characterized as episodic and fragmented in time and space, respectively. This paper which develops this method proposes a new approach to improve 
the monitoring of Siberian forests. The basic sense of this approach is the combined use of microwave remote sensing and modeling tools implemented as a search system of fire-prone zones.

The search and detection of areas susceptible to forest fires range, from detecting the location of combustible materials and sites with abnormal temperatures to diagnosing the occurrence of fire and determining its direction. Historical data on forest are provided by the IL-18 flying laboratory of the Kotelnikov Institute of Radioengineering and Electronics of the Russian Academy of Sciences for the evaluation of DMS parameters and its validation. The global IL-18 monitoring system is shown in Figure 1. The IL-18 instrumental equipment provides measurements of air humidity and temperature, the heat emission of surface covers in the wavelength range from $0.8 \mathrm{~cm}$ to $27 \mathrm{~cm}$. Other devices shown in Figure 1 provide optical images of the land cover and synchronized timing and spatial stabilization of remote sensing measurements.

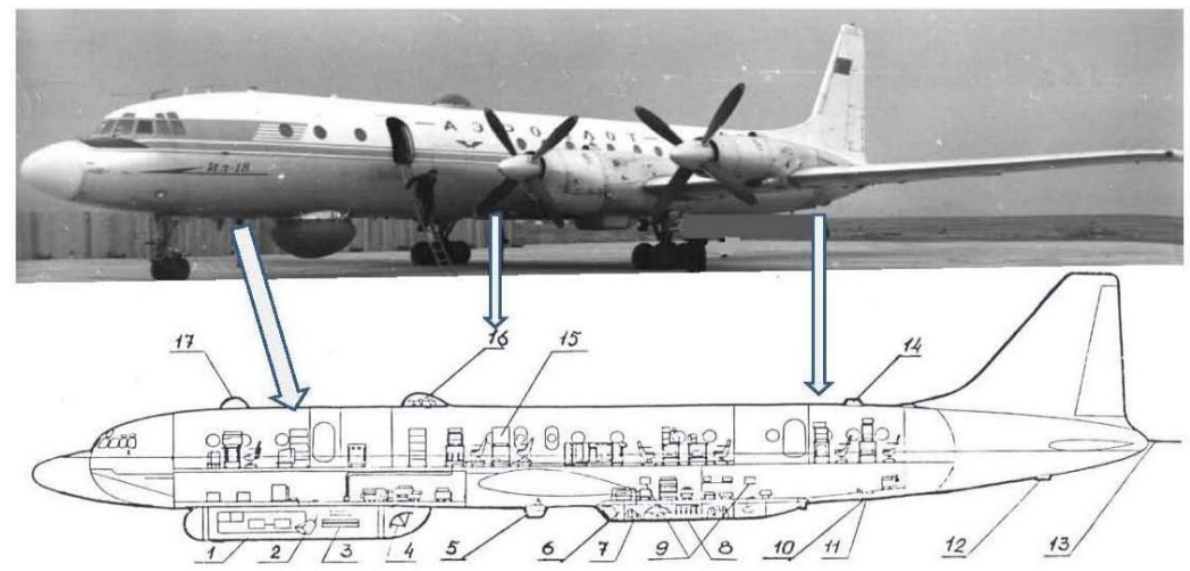

Figure 1. Main layout of the remote sensing systems on-board the IL-18 flying laboratory (hull No 75423). Note: 1,3—-synthetic aperture detectors, wavelengths of 2.0 and $10.0 \mathrm{~cm} ; 2,6$ - trace polarimeters, wavelengths of 0.8 and $2.25 \mathrm{~cm}$; 4 - six-channel scanning polarimeter, wavelengths are $0.8,1.35,2.25$, $5.5,10,21$ and $27 \mathrm{~cm} ; 7,9$-altimeter and interferometer, wavelength is $2.2 \mathrm{~cm}$; 13 -sub-surface sensing station of decimetric range; 5,10,12-large-format and frame TV, aerocamera; 11,14-radiometers of mm range; 16 - radiometers traces, L- band; 15-gravimetric and inertial devices; 17-astro-hatch.

The IL-18 remote sensing platform provides spatial resolution depending on the $H$-altitude of the remote sensing platform and the wavelengths of the microwave sensors. As it is well known, in microwave radiometry the footprint size (pixel diameter) is determined by the following ratio [23]:

$$
D \approx 1.2 H \chi / d
$$

where $D(\mathrm{~m}), H(\mathrm{~m})$ and $d(\mathrm{~cm})$ are the antenna footprint diameter, the altitude of the antenna platform above the Earth's surface and the antenna diameter, respectively; $\chi(\mathrm{cm})$ is the wavelength.

As shown in (1), for the passive microwave radiometry wavelength range, $2.25 \mathrm{~cm}-21 \mathrm{~cm}$, the pixel size ranges from $70 \mathrm{~m}$ at $\chi=2.25 \mathrm{~cm}$ to $700 \mathrm{~m}$ at $\chi=21 \mathrm{~cm}$ for the remote sensing platform altitude, $H=3$ $\mathrm{km}$. The IL-18 remote sensing platform typically had an altitude of 250-600 $\mathrm{m}$ during the measurement implementation [23]. In this case the spatial resolution depends on both the flight altitude and the frequencies of the radiometers used estimated by the equations in Table 1 . If the unmanned helicopter is used as a remote sensing platform, the spatial resolution can be $2.5-25 \mathrm{~m}$. For satellite altitude, $H=$ $600-800 \mathrm{~km}$, pixel size ranges from $15-20 \mathrm{~km}$ at $\chi=2.25 \mathrm{~cm}$ to $140-190 \mathrm{~km}$ at $\chi=21 \mathrm{~cm}$, while other conditions are equal. If the microwave radiometers of wavelengths $0.8,2.25$ and $21 \mathrm{~cm}$ are mounted on an unmanned aircraft vehicle, the DMS can safely detect fire of about 1-2 square meters under the trees at an altitude of about 80-100 m [24-26]. Land observation satellites have spatial resolution ranging from tens of meters to one hundred kilometers depending on the sensors. Satellite measurements such as vegetation indices Normalized Difference Vegetation Index (NDVI) and Leaf Area Index (LAI) are 
used to calculate vegetation parameters, including biomass and evapotranspiration [22]. In general, a more detailed examination of the problem of spatial resolution is carried out when using passive multi-frequency microwave remote sensing by several publications [24,25].

Table 1. Characteristics of the remote sensing sensors which are equipped by the IL-18 platform $[26,27]$.

\begin{tabular}{ccccc}
\hline Frequency $(\mathbf{G H z})$ & Wavelength $\mathbf{( c m )}$ & Pixels/Scan & Resolution $\mathbf{( m )}$ & Mode \\
\hline 37.5 & 0.8 & 32 & $0.04 \times H$ & Scanning \\
\hline 22.2 & 1.35 & 16 & $0.05 \times H$ & Scanning \\
\hline 13.3 & 2.25 & 16 & $0.08 \times H$ & Scanning \\
\hline 5.5 & 5.5 & 6 & $0.13 \times H$ & Scanning \\
\hline 3.0 & 10.0 & 2 & $0.31 \times H$ & Scanning \\
\hline 1.43 & 21 & 2 & $0.65 \times H$ & Twin-beam \\
\hline
\end{tabular}

\subsection{Detection System}

On any temporal and spatial scale, forest fire occurs when there are many natural and anthropogenic conditions: there is extreme air temperature; drought factor is available (often expressed as low relative humidity of forest litter); and human factors such as rural areas and settlements are not far from the forests. Other factors such as thunderstorm activity, topographic factors and wind velocity can also affect the forest fire occurrence. As Pampalony [28] noted, significant progress in the effective monitoring of forest fires for their prior detection is likely to be possible when microwave remote sensing and information-modeling technologies are used. The problem becomes complicated by the conditions in Siberia, where more than $30 \%$ of forests are located in potentially difficult-to-available areas, where land-based measurements capabilities are practically impossible. Therefore, the decision-making system (DMS) proposed in this study is to perform the following:

- Regular environmental monitoring of Siberian forests and data accumulation in the on-board equipment;

- Developing the dynamic series for the element where FFOP is larger at a constant level (usually

$0.5)$ to make a statistical decision about noise or signal character, and

- Detection and diagnosis of burned zones.

The DMS structure shown in Figure 2 has a functional part-the forest fire danger prediction system (FFDPS) elements-described in Table 2.

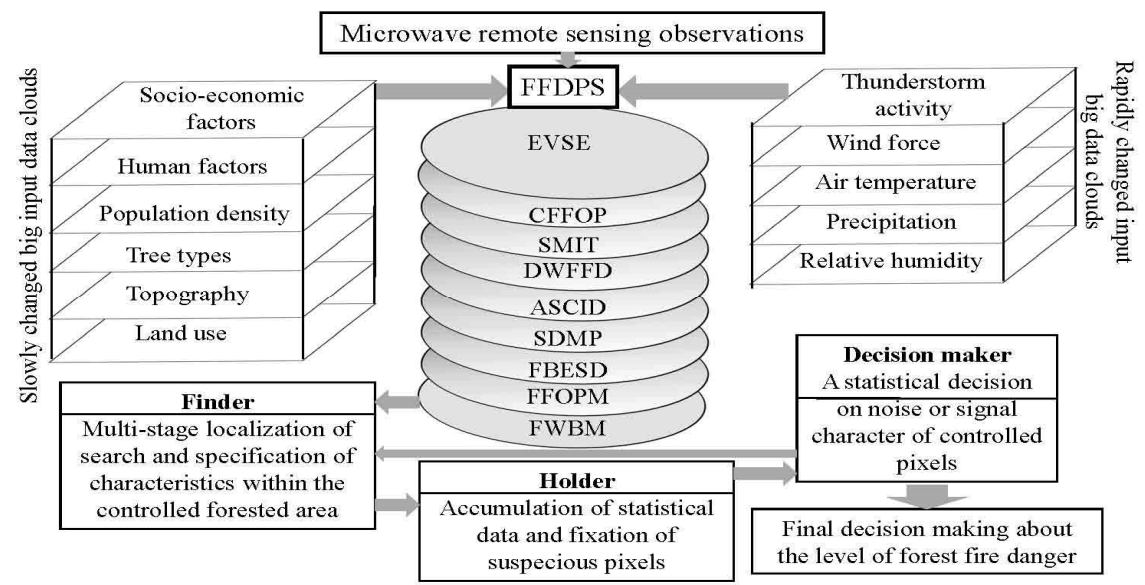

Figure 2. The main operational structure of the decision making system (DMS) as a monitoring system to detect areas prone to forest fires. The items of the forest fire danger prediction system (FFDPS) are described in Table 2. 
Table 2. The operational characteristics of the FFDPS items shown in Figure 2.

\begin{tabular}{ccc}
\hline Sub-Block & Sub-Block Function & References \\
\hline CFFOP & Calculation of the forest fire occurrence probability (FFOP) & {$[8,9]$} \\
\hline SMIT & $\begin{array}{c}\text { Solution of microwave inverse task for estimating volumetric moisture } \\
\text { content in forest soil-litter and canopy. }\end{array}$ & {$[29-31]$} \\
\hline DWFFD & $\begin{array}{c}\text { Evaluation of pre-fire conditions. Definition of weights of the forest fire } \\
\text { danger factors. Detection of both fire-prone pixels and pixels where the } \\
\text { burning process is performed. }\end{array}$ & {$[32,33]$} \\
\hline ASCID & Analysis of slowly changed input data and their updating. & {$[15]$} \\
\hline EVSE & $\begin{array}{c}\text { Evaluation of the vegetation screening effect. } \\
\text { Calculation of forest physical temperatures using the observed } \\
\text { brightness temperatures. }\end{array}$ & {$[34-36]$} \\
\hline SDMP & Sequential decision-making procedure. & {$[37]$} \\
\hline FBESD & Forest biomass estimation via satellite data. & {$[38]$} \\
\hline FWBM & Forest water balance model. Parameterization of the components from \\
the hydrological balance equation. & {$[39-42]$} \\
\hline FFOPM & FFOP mapping. & {$[29]$} \\
\hline
\end{tabular}

Microwave radiometry is a potentially high-performance method for estimating forest phytomass, soil-litter moisture, and mapping water reserves at regional and global scale. The forest is a semi-transparent medium for the L-band wavelengths due to its eco-morphological structure having a horizontal mosaic pattern and a strong vertical stratification. However, there is a serious problem of low spatial resolution when using L-band radiometers. In this case, the spatial resolution of remote sensing observations can be approximately one kilometer when using an aviation platform and many kilometers for the satellites. The IL-18 platform provides spatial resolution in the range of 130 to $650 \mathrm{~m}$ using the radiometers presented in Table 1 and depending on the altitude of the flying platform.

Multiannual remote sensing observations and fragmentary in-situ measurements have contributed to the development of a decision-making system with the following functions:

- Operational control of the regional water cycle, including evaluation of evapotranspiration of forest vegetation, based on current meteorological and geophysical data;

- Calculation of the spatial distribution of the regional parameters of the forest water balance, including the bulk water content of the forest canopy and the soil-litter;

- Detection of fire-prone zones based on the calculation of soil-litter moisture index; and

- Diagnosis of forest fire with fire distribution, zone burning and fire moving direction.

Figure 2 shows the DMS functional structure. The IL-18 flying platform, equipped with measuring instruments, provides operational data to the DMS with traces of its movement with spatial resolution determined according to the radiometers used (see Table 1 ). As is well known, in microwave radiometry the footprint size (pixel diameter) is determined by the wavelength [29]. The general functional scheme of DMS has three subsystems: holder, decision maker, and finder.

Finder detects spatial pixels with very severe fire hazards stored in holder's memory. The decision maker analyzes the input data from the holder and resolves the origin of these pixels from the signal (abnormal) or from the noise (background) [43,44]. As a result, an SDMP block based on this data makes a final decision about the pixel state. This results in an optimization of the monitoring regime and an increased probability of a fire onset. Moreover, the remote sensing platform used can be implemented after a preliminary modeling of the spatial distribution of the forest fire occurrence probability (FFOP), which is one of the functions of the definition of weights of the forest fire danger factors (DWFFD) block. Based on these parameters, access to DMS is provided by available sources, such as meteorological services, satellite observations, natural and anthropogenic databases. Of course, 
the regional forestry service usually has information about potential fire risk areas where fire origin is very likely.

Therefore, the two-stage monitoring process is carried out to detect forest fire-prone pixels, using potential theoretical indices and models at risk of fire, as remote sensing tools to more accurately validate fire-prone pixels. The forest fire risk model is used to assess the status of forest combustible materials, including moss, lichens, leaves, needles, shoots, dry vegetation, peat, wear and other constituents of forest soil-litter. Of course, the moisture content of forest soil-litter is an important parameter for the origin of forest fire. In-situ measurements of this parameter are only possible when small local forest pixels are monitored. In fact, soil-litter moisture from forests is assessed using both ecological models and remote sensing tools $[29,45]$.

\subsection{Probability of Forest Fire Occurrence}

The origin of the forest fire is mainly determined by the water cycle in the forest area being monitored. The quantity and availability of water in the forest ecosystem is a key factor in the fire origin. Krapivin et al. [38] proposed a regional water cycle model (RWCM) where all components of the water cycle in forests can be evaluated. However, this model requires many environmental parameters that are evaluated with high uncertainty or missing numerical values. This is the case when huge forests are considered, such as the Siberian or Russian Far East forests. Therefore, simplified models are considered to reduce the level of uncertainty. For example, Chuvieco et al. [32] proposed an empirical method for extracting the fuel moisture content (FMC) estimated at the baseline values of the normalized difference vegetation index (NDVI) and the leaf area index (LAI).

Drought factors and indices are also introduced to estimate the water content of trees and soil-litter according to meteorological and environmental conditions. Chen et al. [45] introduced the temperature vegetation dryness index (TVDI) using LANDSAT-5 TM data on soil moisture status in the Laoshan Forest Park in Nanjing (China). Sharples et al. [46] studied the McArthur Mark 5 Forest Fire Danger Index (FFDI) and demonstrated its effectiveness in relation to Australia's wildfire risk classification thresholds. Torngern et al. [47] represented soil moisture with Relative Extractable Water (REW) and showed that REW reliably assesses the physiological status of forest ecosystems and forest hydrological cycle data.

The main difference between the forests of Siberia and the Russian Far East from other forests is their vast area (about 8.6 million $\mathrm{km}^{2}$ ) without settlements. The climate in the Siberian taiga is sub-arctic with extreme temperatures ranging from 40 to $-62{ }^{\circ} \mathrm{C}$ and long cold winters and short summers. The temperate rainforests of the Russian Far East (over 3 million $\mathrm{km}^{2}$ ) are poorly understood in terms of the basic types and structure of the ecosystem [47]. As a result, monitoring of these forests has limited means for in-situ observations and the use of remote sensing platforms for continuous measurements. Nevertheless, we use some aspects of a dynamic forest water balance model proposed by Speich et al. [48]. This model is based on 19 parameters that describe many vegetation characteristics and soil properties, the use of which requires in-situ measurements.

The combined use of modeling tools and remote sensing techniques is the optimal and cost-effective approach to detect areas prone to fire in vast forests. The role of human factors, such as the distance of the forest ecosystem from roads, settlements and areas of agricultural activity, may be important in assessing the probability of forest fires occurring only in limited areas of Siberian forests. Human-induced factors play a significant role in zones where the population density exceeds 3.5 individuals $/ \mathrm{km}^{2}$. The causes of taiga fires are mainly related to natural processes such as thunderstorm activity and soil-litter dryness $[45,46,49]$. In other words, soil-litter moisture is more important than any other factor in the occurrence of forest fire. In this way, Figure 3 illustrates the use of the forest water balance model. 


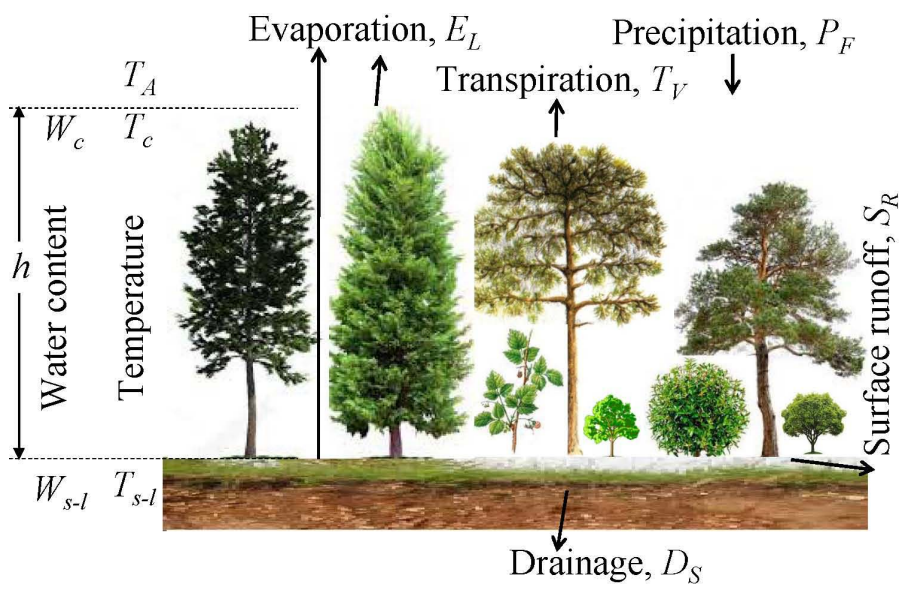

Figure 3. Main scheme of the forest water balance model. Note: $W_{c}$ and $W_{s-l}$ are the water content of the forest canopy and soil-litter, respectively; $T_{A}, T_{c}$ and $T_{s-l}$ are the temperatures of the atmosphere, forest canopy and soil-litter layer, respectively.

The forest fire occurrence probability (FFOP) reflects regional conditions in which the fire risk can range from negligible and unlikely to very serious and very likely, depending on topography, weather, forest type and human factors. These factors are pre-fire conditions, the most important of which are forest soil-litter water content $\left(W_{s-l}\right)$, canopy water content $\left(W_{c}\right)$, temperature $\left(T_{A}, T_{c}\right.$, $\left.T_{s-l}\right)$ and the thunderstorm activity index $(\mu)$. The FFDPS can provide conditions for forest soil-litter moisture estimates in each spatial pixel of a forest being monitored using modeling tools and remote sensing platforms. Weather conditions (temperature, wind and thunderstorm activity) are provided by regional weather centers or are measured directly by flying platform devices or evaluated by satellite data. The activity of a thunderstorm (specific to Siberia) depends on geographical factors and synoptic conditions [50,51]. Mullayarov et al. [51] proposed the following formula for thunderstorm activity (surface discharge) as a function of latitude $\varphi$ :

$$
\mu=\frac{\delta N_{d}}{5.16+2.16 \operatorname{Cos} \varphi} ; 52 \leq \mathrm{N} \leq \varphi \leq 68^{\circ} \mathrm{N} ;
$$

where $\delta$ is the proportionality factor $(0.049 \leq \delta \leq 0.175), N_{d}$ is the number of days with thunderstorms per month. Figure 4 summarizes the existing data that was not incorporated into thunderstorm activity in the Siberian region. The specific density of thunderstorms in various Siberian regions ranges from $1 / \mathrm{km}^{2} / \mathrm{yr}$ to $8.5 / \mathrm{km}^{2} / \mathrm{yr}[52-54]$.

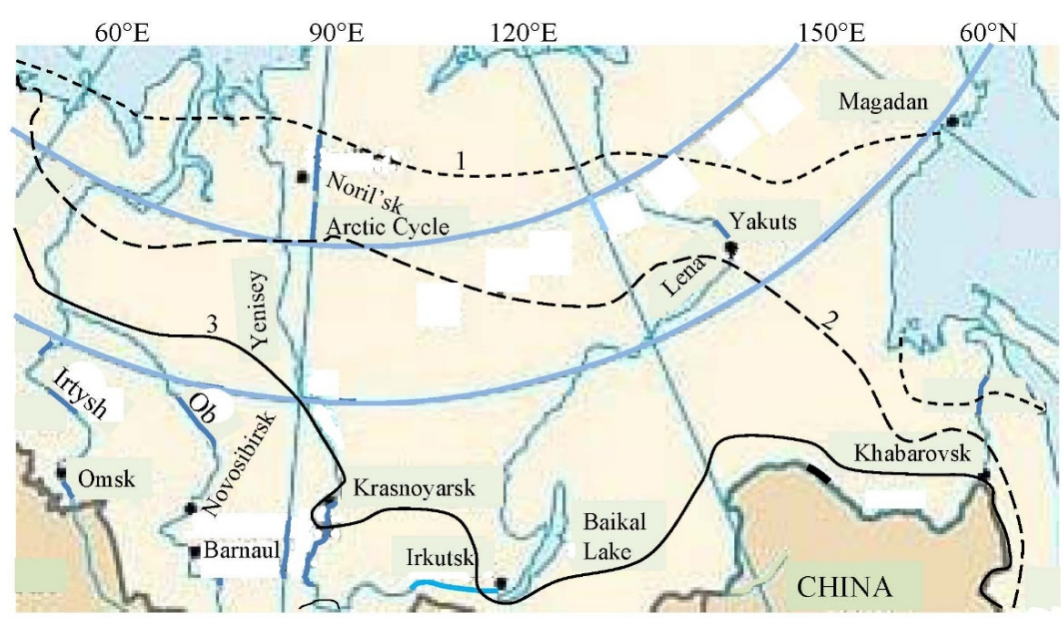

Figure 4. Map of the average annual duration of thunderstorms. North of curves 1, 2 and 3 the duration is up to 10, 20 and 40 hours, respectively. South of curve 3 the duration may reach 60 hours [47-49]. 
Understanding the role of all the factors that cause forest fire has many uncertainties. About $60 \%$ of forest fires in Siberia are caused by thunderstorms. The role of anthropogenic factors in this process is difficult to determine due to the deforestation. Therefore, the FFPDS evaluates the FFOP only taking into account the dynamics of forest soil-litter moisture, air temperature and thunderstorm activity. The air temperature difference in the atmosphere-forest-soil system is usually below $3{ }^{\circ} \mathrm{C}$ [54]: $T_{\mathrm{c}} \approx T_{\mathrm{s}-1} \approx$ $T_{\mathrm{A}}-3$. According to White et al. [13] the following formula of FFOP calculation is used to estimate the average causes of forest fires in Siberia during 2019:

$$
F F O P=\left[1+a_{1} \sqrt{W_{s-l}+W_{c}} \exp \left\{a_{2}\left(M_{s-l}+M_{c}\right)\right\}+\sqrt{1+T_{s-l}} \exp \left\{a_{3} T_{s-l}\right\}+\sqrt{1+T_{c}} \exp \left\{a_{4} T_{c}\right\}+a_{5} \exp \left\{a_{6} \mu\right\}+a_{7} \exp \left\{a_{8} V\right\}\right]^{-1}
$$

where $a_{i}(i=1, \ldots, 8)$ are the coefficients reflecting the average contribution of soil-litter $\left(W_{s-l}\right)$ and canopy $\left(W_{c}\right)$ moisture $(52.3 \%)$, temperature $\left(T_{s-l}\right)$ of soil-litter $(24.7 \%)$, temperature $\left(T_{c}\right)$ of canopy $(16.5 \%)$, thunderstorm activity $(\mu)(3.9 \%)$ and wind speed $(V)(2.6 \%)$ at FFOP level. An analysis of Siberian forest fires statistics for the years 1985-2019 shows that the weights of fire factors vary by region [55]. These contributions correspond to the following weights: $a_{1}=0.0171 ; a_{2}=0.0141 ; a_{3}=$ $-0.123 ; a_{4}=-0.132 ; a_{5}=0.0182 ; a_{6}=-1.713 ; a_{7}=0.0234 ; a_{8}=-0.0312$.

The impact of human factors on the spatial and temporal patterns of forest fires occurrence should be better understood for the Siberian region by taking into account the existence of a criminal component [56]. However, this factor is not addressed here.

The forest soil-litter moisture is assessed by the forest water balance model (FWBM) block based on the following balance equation:

$$
W_{s-l}(\varphi, \lambda, t+\Delta t)=W_{s-l}(\varphi, \lambda, t)+\left\{P_{F}(\varphi, \lambda, t)-E_{L}(\varphi, \lambda, t)-T_{V}(\varphi, \lambda, t)-D_{S}(\varphi, \lambda, t)-S_{R}(\varphi, \lambda, t)\right\} \Delta t
$$

where $\varphi$ and $\lambda$ are the geographical coordinates; $t$ and $\Delta t$ are time and step by time, respectively; the equation's components are shown in Figure 3. Precipitation information is provided by both the observation system and local meteorological services. Evaporation and transpiration dependencies in the leaf area index (LAI) are given by Sun et al. [39] and Pengxin et al. [41]. Hydrological processes such as drainage and surface runoff are described according to Onuchin et al. [35].

Finally, the DMS detects pixels where the forest fire can start and the monitoring of these pixels is transferred to remote sensing platforms for the definition and detection of forest fires. The remote sensing platform then detects pixels with real fires and the CFFOP block evaluates the risk of fire. Table 3 shows the classification of fire risk and hazard. As shown by the multi-year remote sensing measurements using the IL-18 platform [23,29], the optimum frequencies for radiometric detection of forest fires are: $1.43,13.3$ and $37.5 \mathrm{GHz}$ or wavelengths $21,2.25$ and $0.8 \mathrm{~cm}$, respectively. The precision of remote sensing measurements depends on many factors, such as the height of trees, their age and density and the altitude of the remote sensing platform. The information in Table 3 allows the assessment of the forest area in the decision-making process for controlling this area by selecting very dangerous pixels. The solution of microwave inverse task (SMIT) block calculates the forest soil-litter and canopy moisture contents using the Model (4). The DWFFD block is based on remote sensing data that provides pre-fire pixels of fire risk.

Forest fire can be of three types: crown fire, surface fire and ground fire. Actually, these types of fires can be combined. Surface fire consumes soil-litter such as dried leaves, twigs, and duff. The temperature contrasts that can be registered with remote sensing tools allow the identification of these types of fires. According to Krapivin et al. [57] and Chukhlantsev [58] the following equation can be written:

$$
T_{c}\left(1-r_{\chi}-q_{\chi}\right)+k_{s-l}^{\chi} T_{s-l} q_{\chi}+T_{c} q_{\chi}\left(1-r_{\chi}-q_{\chi}\right)\left(1-k_{s-l}^{\chi}\right)=T_{b}(\chi)
$$

where $T_{c}$ is the vegetation canopy temperature $(\mathrm{K}), T_{s-l}$ is the soil-litter temperature $(\mathrm{K}), r_{\chi}$ is the reflection coefficient; $q_{\chi}$ is the transmission coefficient of the vegetation layer, $k_{s-l}^{\chi}$ is the emissivity coefficient of soil-litter media, $T_{b}$ is the brightness temperature recorded by the remote sensing platform 
for wavelength $\chi$. Equation (5) is used for nadir measurements. Many microwave remote sensing measurements using the $1.43 \mathrm{GHz}$ and $13.3 \mathrm{GHz}$ radiometers located on the IL-18 platform have shown that depending on the incidence angle $\theta \in\left[60^{\circ}, 90^{\circ}\right]$, the FFOP fluctuates no more than $5-7 \%$ that is acceptable when diagnosing microwaves in vast forested areas. Questions raised at this point often require special investigations when using the frequencies 1.43 and $37.5 \mathrm{GHz}$ in particular.

Table 3. Scale of forest fire risk and hazard depending on the fire area and soil-litter moisture.

\begin{tabular}{ccccc}
\hline Scale & Fire Risk & Soil-Litter Moisture, $\%$ & Fire Hazard & Fire Area, $\mathbf{k m}^{\mathbf{2}}$ \\
\hline 0 & Fire is absent & $35-40$ & Dangerous does not exist & $0-0.5$ \\
\hline 1 & Unlikely & $30-35$ & Negligible & $0.5-2$ \\
\hline 2 & Possible & $25-30$ & Slight & $2-4$ \\
\hline 3 & Quite possible & $20-25$ & Moderate & $4-6$ \\
\hline 4 & Likely & $15-20$ & Severe & $6-10$ \\
\hline 5 & Very likely & less 15 & Very severe & more 10 \\
\hline
\end{tabular}

The first term of Equation (5) describes the emission from the vegetation layer, the second term corresponds to the emission from the soil-litter, while the third term describes the emission from the vegetation reflected by the soil-litter media and attenuated by a vegetation layer $[29,35,59,60]$. The use of two frequencies in equation (5) generates $T_{c}(\mathrm{~K})$ and $T_{s-l}(\mathrm{~K})$ values in each pixel of the fire hazard zone allowing improved meteorological information and fire zone detection. In this case, the system of two equations can be written for frequencies 13.3 and $37.5 \mathrm{GHz}$ (wavelength 2.25 and 21 $\mathrm{cm}$ ), a solution of which yields physical temperatures values of the forest canopy $T_{\mathcal{c}}$ and the soil-litter layer $T_{s-l}$. Coefficients of Equation (5) were assessed during IL-18 operations and based on literature sources $[23,33,34,58]$.

Forest canopy moisture (FCM) is estimated by the following Equation (6) [60]:

$$
F C M=d(M P D I)^{b}-1
$$

where $d$ and $b$ are empirical coefficients whose values depend on the vegetation type and the wavelength [59-61]. The values of these coefficients are estimated during the contemporary FCM and MPDI measurements in selected pixels located in Irkutsk region (Table 4). The FCM is evaluated by the forest water balance model (block FWBM). The microwave polarization difference index (MPDI) is calculated by the following Equation (7):

$$
M P D I=\left(T_{b}^{v}-T_{b}^{h}\right) /\left(T_{b}^{v}+T_{b}^{h}\right)
$$

Table 4. Description of weighted coefficients values in Equation (6).

\begin{tabular}{ccccc}
\hline \multirow{2}{*}{ Type of Soil-Plant Formation } & \multicolumn{4}{c}{ Wavelength, $\chi$} \\
\cline { 2 - 5 } & \multicolumn{2}{c}{$\chi=2.25 \mathrm{~cm}$} & $\boldsymbol{b}$ & $\boldsymbol{d}$ \\
\cline { 2 - 5 } & $\boldsymbol{b}$ & $\boldsymbol{d}$ & -1.434 & 0.077 \\
\hline Mid-taiga forests & -0.716 & 0.121 & -0.793 & 0.216 \\
\hline North-taiga forests & -0.772 & 0.151 & -0.816 & 0.149 \\
\hline Mixed forests & -0.676 & 0.212 & -0.802 & 0.284 \\
\hline South-taiga forests & -0.734 & 0.309 & -0.742 & 0.084 \\
\hline Forest-tundra & -0.783 & 0.097 & -0.699 & 0.234 \\
\hline Broad-leaved forests & -0.756 & 0.128 & &
\end{tabular}




\section{Results and Discussion}

The study was conducted in Siberia over the period 1985-2019, using DMS along with the IL-18 remote sensing platform and satellite data $[62,63]$. Siberian forests have always suffered from fires during May-September each year. 2019 was a record year for forest fires totaling 14.9 million ha. The DMS calculates the regional components of the water cycle in real-time mode based on the meteorological data provided by the Siberian meteorological service of Russia. The classification and spatial distribution of Siberian soil-plant formations (SPF) has been approved by Basilevich [58] according to the specifications of Krapivin et al. [38] and Krestov [64]. Table 5 lists the main types of SPF and their characteristics. The SPF is assumed to be evenly distributed over each spatial pixel $\Delta \varphi \times$ $\Delta \lambda$ where $\Delta \varphi$ and $\Delta \lambda$ are the geographical pixel sizes of latitude $\varphi$ and longitude $\lambda$, respectively. Other parameters for DMS operation are: $\Delta \varphi=\Delta \lambda=10^{\prime}, \Delta t=1$ day.

Table 5. Quantitative characteristics of soil-plant formations (SPFs) covering Siberian areas where fire is possible.

\begin{tabular}{|c|c|c|c|c|}
\hline Type of Soil-Plant Formation & $\begin{array}{c}\text { Formation Area } \\
\left(10^{6} \mathrm{~km}^{2}\right)\end{array}$ & $\begin{array}{c}\text { Daily Production } \\
\left(\mathrm{g} / \mathrm{m}^{2} / \text { day }\right)\end{array}$ & $\begin{array}{l}\text { Phytomass } \\
\left(\mathrm{kg} / \mathrm{m}^{2}\right)\end{array}$ & $\begin{array}{l}\text { Dead Organic } \\
\text { Matter }\left(\mathrm{kg} / \mathrm{m}^{2}\right)\end{array}$ \\
\hline Mid-taiga forests & 0.88 & 4.2 & 22.5 & 10.8 \\
\hline North-taiga forests & 0.83 & 3.6 & 10.0 & 8.1 \\
\hline Mixed forests & 0.24 & 5.8 & 25.0 & 25.1 \\
\hline South-taiga forests & 1.08 & 4.3 & 23.5 & 14.5 \\
\hline Forest-tundra & 0.29 & 4.3 & 3.8 & 9.0 \\
\hline Forest-steppes & 0.31 & 4.9 & 1.9 & 38.0 \\
\hline Broad-leaved forests & 0.23 & 8.3 & 45.0 & 24.8 \\
\hline Total & 3.86 & 35.4 & 131.7 & 130.3 \\
\hline
\end{tabular}

The multi-year exploitation of the IL-18 remote sensing platform shown in Figure 1 allows new insights into Figures 5-9 and Tables 6 and 7. Tables In these cases, the identification of the fire zone was accomplished with both a video-camera and the Equation (5) solution for wavelengths of 2.25 and $21 \mathrm{~cm}$. Information from forestry services was used simultaneously. As a result, spectral images of the fire zones were obtained (Figure 7) which can used automatically to identify the fire zones. Figure 5 shows the variations of brightness temperatures in the case of IL-18 flying over the southern taiga, the Village of Strelka (where the Angara River flows into the Yenisey River). Brightness temperatures above forest fires have a typical spatial distribution that reliably reflects the fire zones. Figures 6 and 7 illustrate the brightness temperature levels depending on the fire state. Knowing the structure of the forest fire simplifies the way to extinguish it. Microwave radiometers can detect and distinguish fire categories such as smoked area, fire front, burning and burnt zones. Typical levels of brightness temperatures in these zones are shown in Figures 6 and 7 which allow a detailed diagnosis of the fire structure by assessing the accuracy of the hazard. Figure 8 shows the dependence of brightness temperatures on the soil-litter moisture dynamics after rainfall. The levels of accuracy of the results in Table 7 were estimated by means of the average of the differences between the modeling result, the IL-18 measurement and the in-situ data. Measurements were performed using 1.43 and 13.3 $\mathrm{GHz}$ radiometers with spatial resolution of 215 and $43 \mathrm{~m}$, respectively. The recording time does not exceed 1 second. To assess the influence of the discrepancy between the pixels on the brightness temperatures, the measurements were conducted both in the nadir and the slant with the incidence angle $\theta \in\left(60^{\circ}, 90^{\circ}\right)$. 


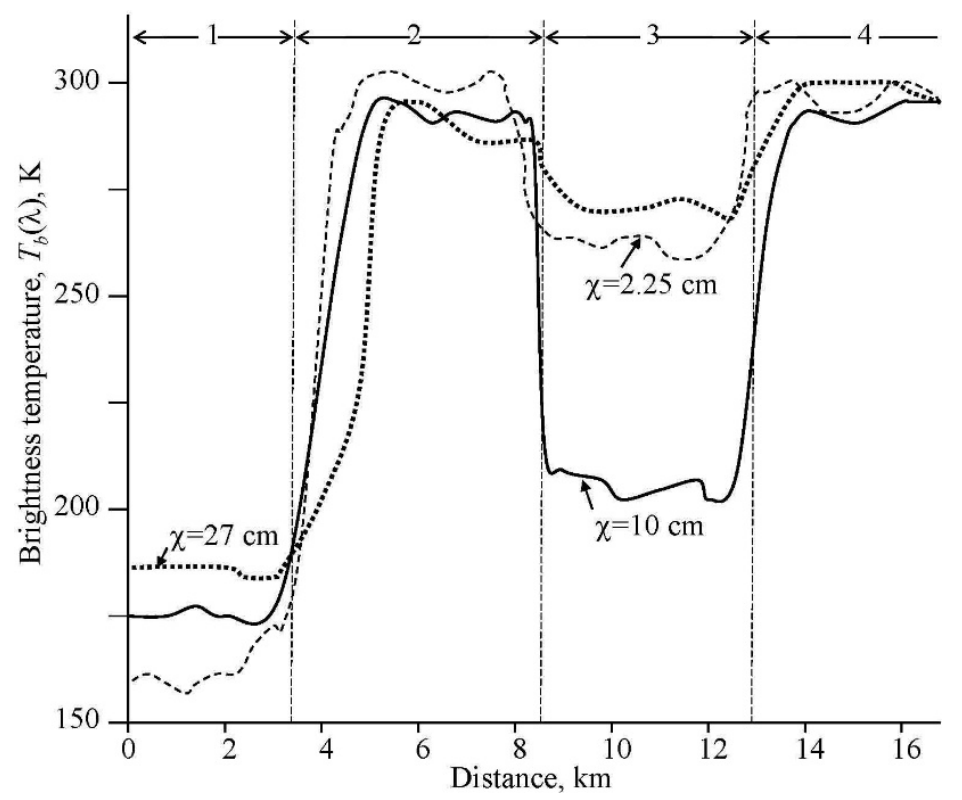

Figure 5. Typical brightness temperature distributions along the IL-18 trace above the pixels near the Yenisey River recorded by different microwave radiometers. Brightness temperatures were recorded on August 14, 1989, 5 days after the rainfall. The numbers above the curves indicate the land cover: 1-Yenisey River zone, 2-taiga, 3-peat bog and 4-taiga.

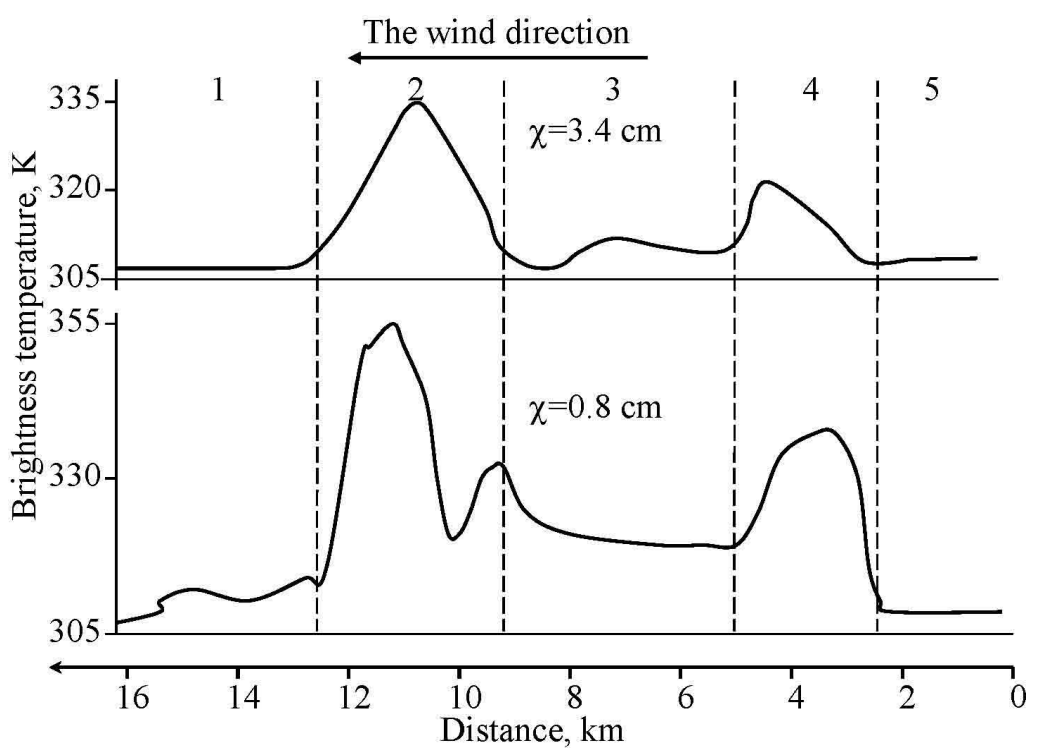

Figure 6. Typical brightness temperature distributions recorded along the IL-18 trace above the active fire pixels. The measurements were made on July 21, 1998 in the Irkutsk region, 75 km north of Irkutsk, a south-taiga forest. Numbers 1-5 identify forest fire zones: 1-smoky area, 2-fire front, 3-burning zone, 4-fire back and 5-forest. 


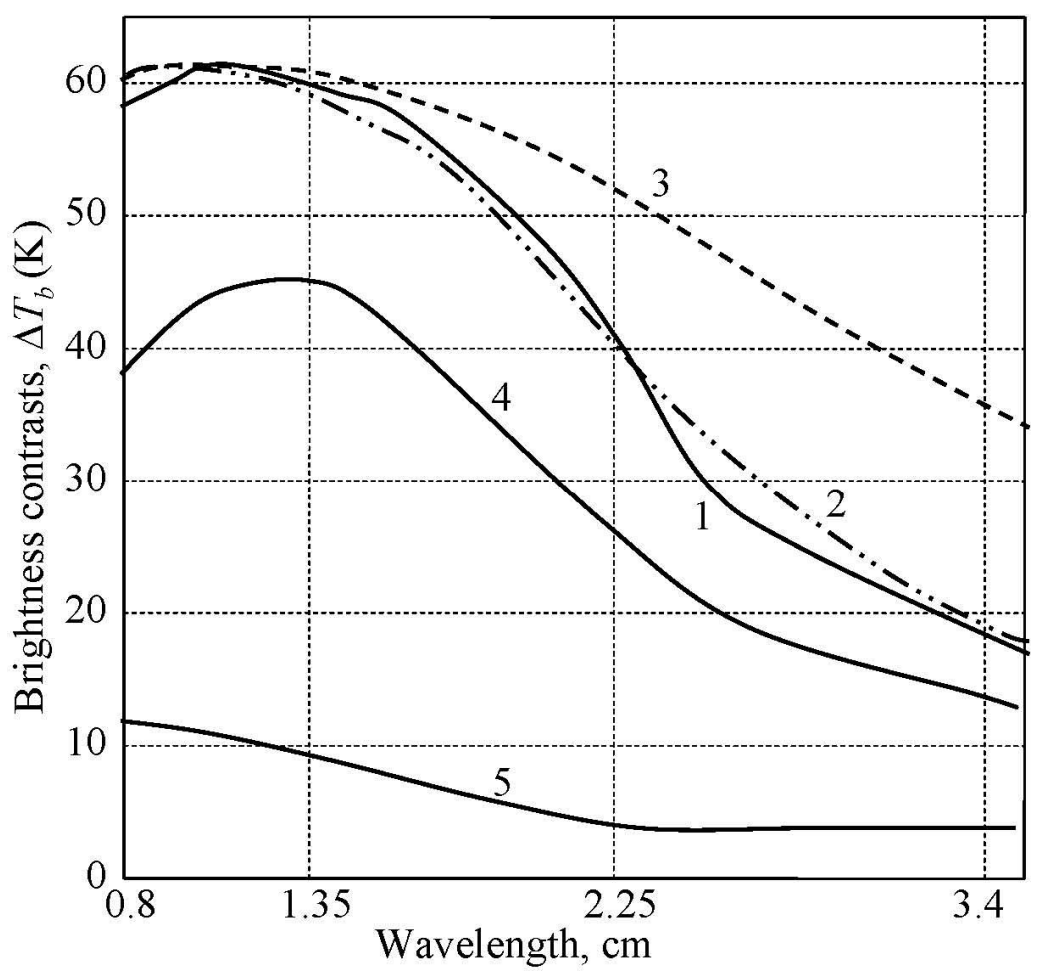

Figure 7. Averaged spectral characteristics of various fire zones: 1-front, 2-left flank, 3-right flank, 4-back and 5-burnt zone. Results presented were obtained during flight experiments from 2003 to 2009 and in $2016[23,26,33,57]$.

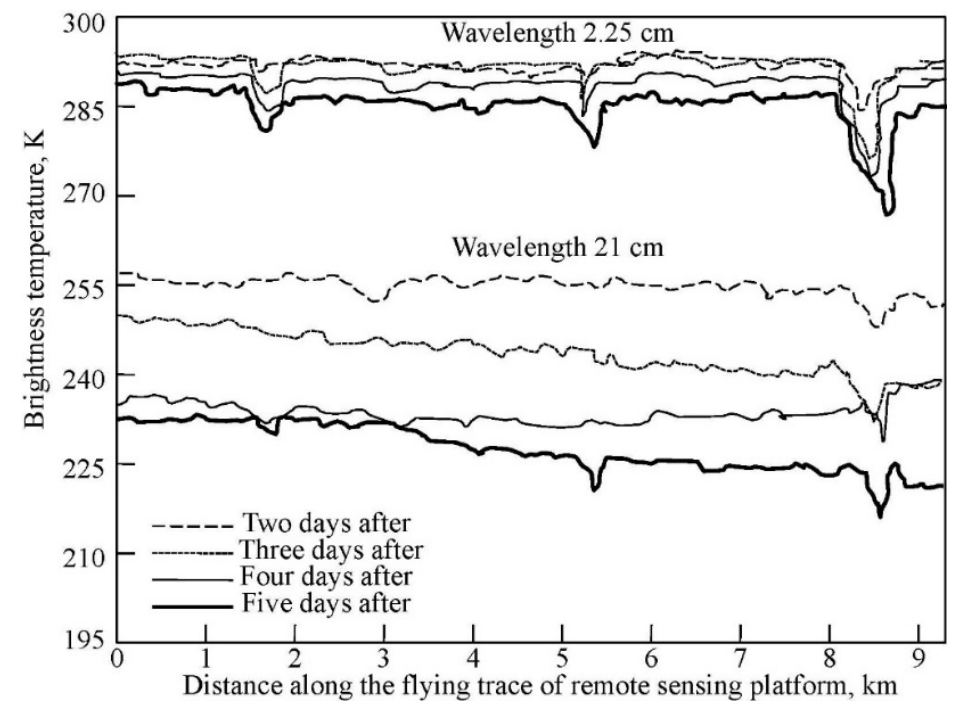

Figure 8. Spatio-temporal variation of brightness temperature with time after rainfall. Measurements were made from August 10, 2007 when it was raining (15 mm). 


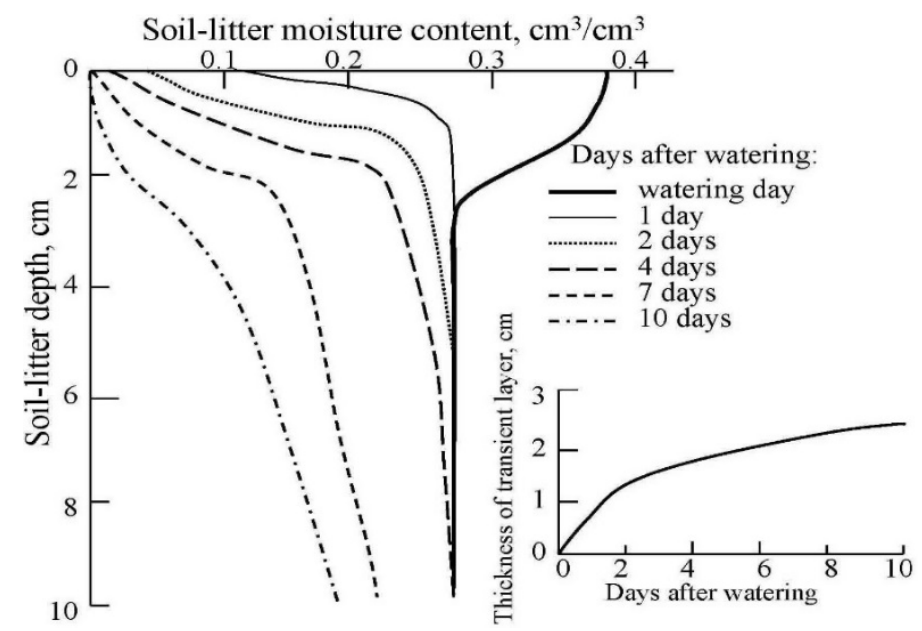

Figure 9. Experimental soil-litter moisture profiles in soil-litter drying dynamics. The depth of the transitional layer is $2.25 \pm 0.7 \mathrm{~cm}$, the soil-litter depth ranges from $0 \mathrm{~cm}$ to $10 \mathrm{~cm}$. Measurements were made during 2003-2009 and 2016 [23,26,33,57].

Table 6. Soil-litter moisture (\%) dynamics after rainfall. The soil-litter thickness is $10.7 \mathrm{~cm}$. The water drainage factor to soil is 0.7 . The canopy interception coefficient is 0.2 . The measurements were carried out in 2003-2008 during the Russian-USA and Russian-Bulgaria ecological missions [29,38,57].

\begin{tabular}{ccccccccc}
\hline \multirow{2}{*}{ Days after Rainfall } & \multicolumn{7}{c}{ Rainfall, cm } \\
\cline { 2 - 9 } & $\mathbf{0 . 1}$ & $\mathbf{0 . 3}$ & $\mathbf{0 . 5}$ & $\mathbf{1}$ & $\mathbf{2}$ & $\mathbf{3}$ & $\mathbf{4}$ & $\mathbf{5}$ \\
\hline 1 & 52 & 65 & 71 & 77 & 78 & 80 & 89 & 94 \\
\hline 2 & 29 & 32 & 39 & 42 & 49 & 55 & 68 & 89 \\
\hline 4 & 21 & 23 & 29 & 32 & 37 & 42 & 54 & 74 \\
\hline 6 & 18 & 19 & 25 & 28 & 32 & 35 & 48 & 65 \\
\hline 8 & 17 & 17 & 22 & 25 & 27 & 29 & 42 & 57 \\
\hline 10 & 16 & 16 & 19 & 22 & 25 & 28 & 37 & 51 \\
\hline 15 & 15 & 16 & 18 & 22 & 23 & 24 & 28 & 39 \\
\hline 20 & 13 & 14 & 15 & 21 & 22 & 22 & 23 & 29 \\
\hline 30 & 11 & 12 & 13 & 17 & 17 & 17 & 19 & 21 \\
\hline
\end{tabular}

Table 7. The precision of the proposed method for diagnosing forest areas by detecting forest fire zones. The pixel's geographical coordinates correspond to its top left and bottom right angles.

\begin{tabular}{|c|c|c|c|c|c|c|}
\hline \multirow{2}{*}{ No } & \multirow{2}{*}{$\begin{array}{c}\text { Pixel } \\
\text { Geographical Coordinates }\end{array}$} & \multicolumn{5}{|c|}{ Soil-Litter Moisture, \% } \\
\hline & & Model & IL-18 & Difference & In-situ Data & Average Error, \% \\
\hline 1 & $\begin{array}{l}56^{\circ} 17^{\prime} 17^{\prime \prime} \mathrm{N}, 95^{\circ} 54^{\prime} 21^{\prime \prime} \mathrm{E} ; \\
56^{\circ} 17^{\prime} 10^{\prime \prime} \mathrm{N}, 95^{\circ} 54^{\prime} 28^{\prime \prime} \mathrm{E}\end{array}$ & 15.2 & 14.1 & 1.1 & 14.4 & 3.7 \\
\hline 2 & $\begin{array}{l}49^{\circ} 51^{\prime} 42^{\prime \prime} \mathrm{N}, 129^{\circ} 48^{\prime} 25^{\prime \prime} \mathrm{E} \\
49^{\circ} 51^{\prime} 35^{\prime \prime} \mathrm{N}, 129^{\circ} 48^{\prime} 32^{\prime \prime} \mathrm{E}\end{array}$ & 13.6 & 10.2 & 3.4 & 12.7 & 15.5 \\
\hline 3 & $\begin{array}{l}52^{\circ} 57^{\prime} 21^{\prime \prime} \mathrm{N}, 104^{\circ} 19^{\prime} 06^{\prime \prime} \mathrm{E} ; \\
52^{\circ} 57^{\prime} 14^{\prime \prime} \mathrm{N}, 104^{\circ} 19^{\prime} 13^{\prime \prime} \mathrm{E}\end{array}$ & 11.3 & 10.1 & 1.2 & 9.8 & 8.2 \\
\hline 4 & $\begin{array}{l}51^{\circ} 59^{\prime} 51^{\prime \prime} \mathrm{N}, 79^{\circ} 15^{\prime} 48^{\prime \prime} \mathrm{E} \\
51^{\circ} 59^{\prime} 44^{\prime \prime} \mathrm{N}, 79^{\circ} 15^{\prime} 55^{\prime \prime} \mathrm{E}\end{array}$ & 18.1 & 16.8 & 1.3 & 16.9 & 3.6 \\
\hline 5 & $\begin{array}{l}50^{\circ} 47^{\prime} 14^{\prime \prime} \mathrm{N}, 114^{\circ} 29^{\prime} 17^{\prime \prime} \mathrm{E} \\
50^{\circ} 47^{\prime} 07^{\prime \prime} \mathrm{N}, 114^{\circ} 29^{\prime} 24^{\prime \prime} \mathrm{E}\end{array}$ & 13.7 & 11.9 & 1.8 & 10.6 & 16.8 \\
\hline 6 & $\begin{array}{l}51^{\circ} 57^{\prime} 39^{\prime \prime} \mathrm{N}, 79^{\circ} 13^{\prime} 48^{\prime \prime} \mathrm{E} \\
51^{\circ} 57^{\prime} 32^{\prime \prime} \mathrm{N}, 79^{\circ} 13^{\prime} 55^{\prime \prime} \mathrm{E}\end{array}$ & 35.4 & 33.7 & 1.7 & 34.3 & 3.1 \\
\hline
\end{tabular}


Modeling the water balance of the forest ecosystem provides the separation of the pixels with the pre-fire state. Each type of trees has a specific nature of absorption and loss of rain-water through evapotranspiration. Block FWBM carries out the water cycle model taking into account the existing knowledge about the characteristics of soil-plant formations from Table 5. Knowledge of the water content dynamics in the forest canopy and its vertical distribution in soil-litter layer after rainfall helps identify fire-prone pixels more accurately.

The FFOP index reflects the combined role of such environmental characteristics as thunderstorm activity, soil-litter moisture, and temperature in a potential fire origin. Thunderstorm activity in the Siberian region is closely linked to the presence of developed cloudiness in the area and the passage of the cyclonic fronts presented in hydrometeorological forecasts [65]. Soil-litter moisture is calculated from Model (4) and assessed by remote sensing measurements [29]. Table 6 and Figure 9 show the patterns of changes in soil-litter moisture after precipitation. Lee et al. [66] examined the soil-litter moisture content in relation to its dynamics, depending on precipitation events classified as small $(<5$ $\mathrm{mm}$ ) or large $(>5 \mathrm{~mm}$ ) events. Table 6 and Figure 9 show the soil-litter moisture during the stabilized drying process.

The traditional concept of forest fires in the Siberian areas in 2019 acquired the dangerous aspects associated with the increased risk to people and habitats. The complexity of the problem of forest fires management is complicated by the fact that the majority of fires occur in inaccessible areas for in-situ observations. The absence of remote sensing platforms aimed at monitoring forested areas in present-day Russia limits the control of fire hazard and reduces the effectiveness of fire extinguishing services.

Table 7 shows the precision of the proposed method of diagnosing forest areas by detecting zones where there is potential forest fire. We see that Model (4) yields overestimated values of soil-litter moisture compared to remote sensing data. Comparison with in-situ measurements shows that both Model (4) and remote sensing observations provide acceptable precision for reliable decision making regarding the probability of forest fire occurring. Indeed, the forests in each pixel started several days after soil-litter or canopy moisture was less than 26-30\%. For example, in case 1 of Table 7 , pixels with soil-litter moisture below 18\% were detected on August 4, 2019 and the ignition changed on August 8, 2019. These pixels are located near the Village Karapsel of Krasnoyarsk Krai. Case 2 belongs to the Village Bureya in the Amur Oblast. In this case, the fire risk pixels were identified on May 11, 2019 and the forest ignition changed on May 14, 2019. In this case, three hazardous forest fire pixels were identified on May 4, 2019 near the Village Gorohovo, about $70 \mathrm{~km}$ from Irkutsk City and the demonstrated pixel ignition process started on May 8,2019. Cases 4 and 5 show the level of DMS performance for detecting zones with high probability of fire occurrence near Village Nevodnoe (Altaiskii Krai) in 2010 and Village Bayan-Bulak (Transbaikalia, Buriatia) in 2012, respectively. In case 6 , the probability of fire occurrence is no longer $10-12 \%$.

Figure 10 presents the DMS results for the spatial distribution of FFOP within the digital scale calculated for July 20, 2019. Comparison with NASA EOSDIS GIBS (Data and Information System, Global Imagery Browse Services) data for forest fires in Siberia in July 2019 did not detect significant discrepancies. Such digital maps help estimate the risk of forest fire in almost each pixel and solve the task of optimizing the distribution of remote sensing tools to control the most dangerous areas. The obtained FFOP rating matrix can be used for the decision-making process of detecting and predicting the occurrence of forest fire. 


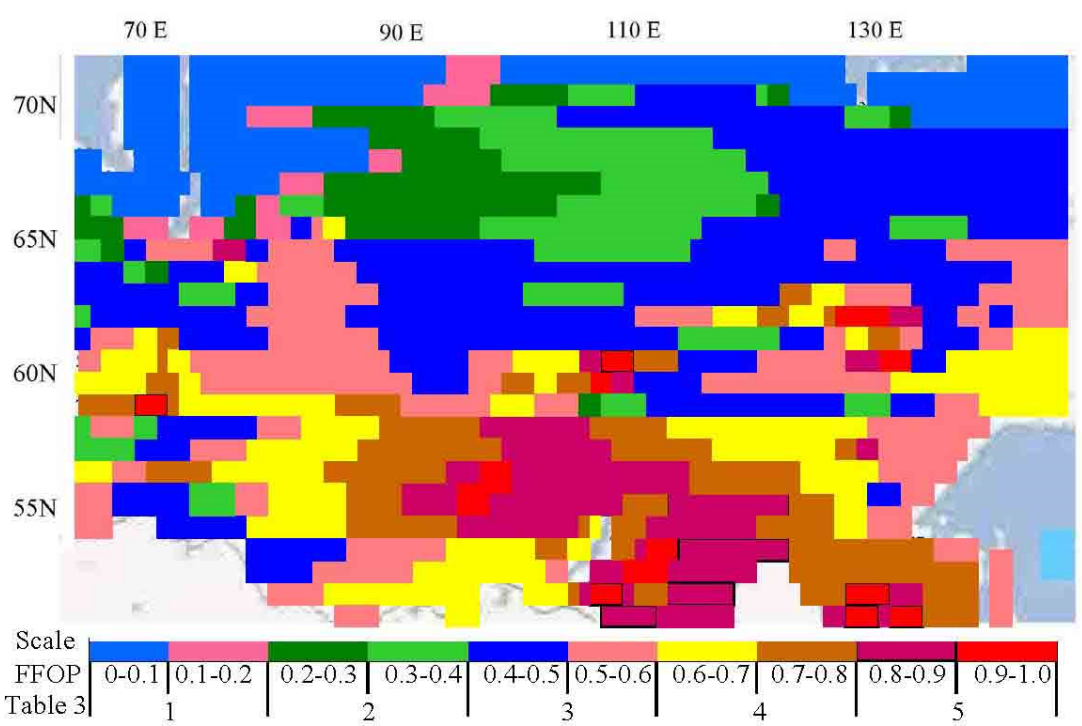

Figure 10. Spatial distribution of FFOP as well as the fire risk and hazard levels in Siberia on 20 July 2019.

\section{Conclusions}

This article proposes a cost-effective monitoring system for the operational detection of areas affected by forest fires. It is based on the IL-18 remote sensing platform equipped with microwave radiometers ranging from 0.8 to $27 \mathrm{~cm}$ wavelengths and a decision-making algorithm that provides for the investigation and identification of fire-prone zones in a fixed geographic area (pixels). A decision-making algorithm is presented that aims to analyze the data flows from devices located on the remote sensing platform to calculate the probability of forest fire occurring in the pixels. The results presented during the long-time exploitation of IL-18 demonstrate acceptable precision that can be achieved by DMS.

It is certain that huge areas of Siberia introduce significant uncertainties about the types of soil-plant formations found in many pixels as well as multi-frequency observations that have shown that forest emissivity depends on the age of the trees, the stand biomass tree density and the tree height. In this case, the uncertainty level of the brightness temperatures depends on the vegetation heterogeneity in the spatial resolution pixel. The main problem in accurately estimating real spatial resolution when used at time different frequencies is the fuzziness of the boundaries between the spatial resolution pixels for these frequencies. These uncertainties are usually overcome by using MPDI-NDVI relationships provided by the NOAA-AVHRR sensor $[67,68]$. Specifically, NDVI contributes to the estimation of various vegetation parameters, including fractional cover, LAI, biomass, and photosynthetic activity. Corresponding algorithms for the numerical evaluation of these parameters are described in Kondratyev et al. [68] and Krapivin et al. [38]. Table 4 shows that MPDI is sensitive to the total water content of the vegetation per unit area and is dependent on the forest type. The detailed study of MPDI for different soil cover classes requires special attention to their microwave characteristics [35]. Moreover, the Siberian region is characterized by a mosaic of tree types of various ages and structures, the relevant information of which may be unreliable. Therefore, a detailed study of Siberian forests is required [69].

The DMS structure was synthesized in such a way as to have the maximum universal availability of flow information blocks among which it is controlled only by a particular information path. This structure allows for arbitrary replacement or addition of functional blocks without modifying other blocks. The DMS input information can be modified within the structure shown in Figure 2 . This study used a limited list of input data provided by regional forestry services and remote sensing tools. There are obvious inaccuracies in the description of soil-plant formations within a limited number of pixels. However, the results of this study indicate that DMS provides useful data on the spatial distribution of soil-litter water content and the probability of forest fire occurrence (see 
Figure 10). This study shows that combined modeling and remote sensing tools allow repeated and consistent coverage in large forest areas to classify spatial pixels at risk of fire.

The main question raised here is the DMS validation. The results of Table 7 and Figure 10 show that the accuracy of the soil-litter moisture evaluations varies significantly and the FFOP spatial distribution agrees with the real fires distribution recorded in July 2019. However, it is acceptable given the complexity of the problem. The main idea of this work was to propose a new monitoring structure for the operational diagnosis of huge forest fire areas in the case of the study of Siberia as the most important component of global climate change.

Preliminary results of this study have shown effective frequencies for more accurate estimation of $T_{c}$ and $T_{s-l}-1.43 \mathrm{GHz}(\chi=21 \mathrm{~cm}), 13.3 \mathrm{GHz}(\chi=2.25 \mathrm{~cm})$ and $37.5 \mathrm{GHz}(\chi=0.8 \mathrm{~cm})$. A choice of frequencies depending on tree heights can improve DMS results. It is obvious that increasing tree height requires a reduction in microwave frequencies. These and other modifications to the current DMS can greatly increase their accuracy. In addition to exploring the information-modeling method to improve forest fire prevention, the Russian Forest Service could improve fire detection and forecasting technologies to address existing information uncertainties that could potentially reduce the risk of forest fires. IL-18 instrumental equipment helps reduce uncertainties due to the use of optical tools and trace polarimeters. Described here DMS can adopt other remote sensing platform that is necessarily equipped with microwave radiometers.

As a field of further research, the DMS technique with another detailed description of SPF in Siberia or any forest area should be studied taking into account additional features of non-linear interactions between the components of the climate system involved in forest fires. The authors are working in this direction [70-77].

Author Contributions: C.A.V. and V.F.K. conceived the study design, developed the models and drafted the manuscript; F.A.M. was involved in data acquisition and analysis and worked on aspects of the experiment evaluation. All authors have read and agreed to the published version of the manuscript.

Funding: This work was partially supported by the Russian Foundation for Basic Research, Project No. 19-07-00443-a.

Acknowledgments: The authors would like to thank the user community for their useful feedback during this research process.

Conflicts of Interest: The authors declare no conflict of interest. The funders had no role in the design of the study; in the collection, analyses, or interpretation of data; in the writing of the manuscript, or in the decision to publish the results.

\section{References}

1. Alkhatib, A. A Review on forest fire detection techniques. Int. J. of Distrib. Sens. Netw. 2014, 10, 1-12. [CrossRef]

2. Ponomarev, E.I.; Ponomareva, T.V.; Prokushkin, A.S. Intraseasonal dynamics of river discharge and burned forest areas in Siberia. Water 2019, 11, 1146. [CrossRef]

3. Eskandari, S. A new approach for forest fire risk modeling using fuzzy AHP and GIS in Hyrcanian forests of Iran. Arabian J. Geosci. 2017, 10, 190-204. [CrossRef]

4. Krapivin, V.F.; Varotsos, C.A. Modelling the $\mathrm{CO}_{2}$ atmosphere-ocean flux in the upwelling zones using radiative transfer tools. J. Atmos. Solar-Terr. Phys. 2016, 150, 47-54. [CrossRef]

5. Varotsos, C.; Assimakopoulos, M.N.; Efstathiou, M. Long-term memory effect in the atmospheric $\mathrm{CO}_{2}$ concentration at Mauna Loa. Atmos. Chem. Phys. 2007, 7, 629-634. [CrossRef]

6. Kondratyev, K.Y.; Varotsos, C. Atmospheric greenhouse effect in the context of global climate change. Il Nuovo Cimento C 1995, 18, 123-151. [CrossRef]

7. Jafarzadeh, A.A.; Mahdavi, A.; Jafarzadeh, H. Evaluation of forest fire risk using the Apriori algorithm and fuzzy c-means clustering. J. Forest Sci. 2017, 63, 370-380. [CrossRef]

8. Chowdhury, E.H.; Hassan, Q.K. Development of a New Daily-scale forest fire danger forecasting system using remote sensing data. Remote Sens. 2015, 7, 2431-2448. [CrossRef] 
9. Dowdy, A.J.; Mills, G.A.; Finkele, K.; de Groot, W. Australian Fire Weather as Represented by the McArthur Forest Fire Danger Index and the Canadian Forest Fire Weather Index; CAWCR Technical Report No. 10; The Centre for Australian Weather and Climate Research: Melbourne, Australia, 2009; 85p.

10. Ganteaume, A.; Camia, A.; Jappiot, M.; San Miguel-Ayanz, J.; Long-Fournel, M.; Lampin, C. A Review of the main driving factors of forest fire ignition over Europe. Environ. Manag. 2013, 51, 651-662. [CrossRef]

11. Kim, S.J.; Lim, C.-H.; Kim, G.S.; Lee, J.; Geiger, T.; Rahmati, O.; Son, Y.; Lee, W.-K. Multi-temporal analysis of forest fire probability using socio-economic and environmental variables. Remote Sens. 2019, 86, 86. [CrossRef]

12. Mireku-Guimah, Y.D.; Duker, A.A. Review of methods for modeling forest fire risk and hazard. Afr. J. Environ. Sci. Technol. 2015, 9, 155-165. [CrossRef]

13. White, B.; White, L.; Ribeiro, G.; Fernandes, P. Development of a fire danger index for eucalypt plantations in the northern coast of Bahia, Brazil. Floresta 2013, 43, 601-610. [CrossRef]

14. Gai, C.; Weng, W.; Yuan, H. GIS-based forest fire risk assessment and mapping. In Proceedings of the Fourth International Joint Conference on Computational Sciences and Optimization, Yunnan, China, 15-19 April 2011; IEEE: Piscataway, NJ, USA, 2011; pp. 1240-1244. [CrossRef]

15. Varotsos, C.A.; Krapivin, V.F. A new big data approach based on geoecological information-modeling system. Big Earth Data 2017, 1, 47-63. [CrossRef]

16. Krapivin, V.F.; Nitu, C.; Varotsos, C.A. Remote Sensing Tools and Ecoinformatics; Matrix Rom: Bucharest, Romania, 2019; 332p.

17. Varotsos, C.; Krapivin, V.F. Microwave Remote Sensing Tools in Environmental Science; Springer: London, UK, 2020. (in press)

18. Sharkov, E.A. Passive Microwave Remote Sensing of the Earth; Physical foundation; Springer: London, UK, 2003; $615 \mathrm{p}$.

19. Chukhlantsev, A.A. Microwave emissions and scattering from vegetation canopies. J. Electromagn. Waves Appl. 1992, 6, 1043-1068.

20. Krüll, W.; Tobera, R.; Willms, I.; Essen, H.; Wahl, N. Early forest fire detection and verification using optical smoke, gas and microwave sensors. Proc. Engin. 2012, 45, 384-394. [CrossRef]

21. Statista Research Department. Russian Regions with the Largest Area Burnt by Forest Fires 2019. Available online: https://www.statista.com/statistics/1036723/russia-area-burnt-by-forest-fires-by-region/ (accessed on 8 January 2020).

22. Eugenio, F.C.; dos Santos, A.R.; Fiedler, N.C.; Ribeiro, G.A. Applying GIS to develop a model for forest fire risk: A case study in Espírito Santo, Brazil. J. Environ. Manag. 2016, 173, 65-71. [CrossRef]

23. Krapivin, V.F.; Shutko, A.M. Information Technologies for Remote Monitoring of the Environment; Springer/Praxis: Chichester, UK, 2012; 498p. [CrossRef]

24. Li, Y.; Hu, W.; Chen, S.; Zhang, W.; Guo, R.; He, J.; Ligthart, L. Spatial resolution matching of microwave radiometer data with convolutional neural network. Remote Sens. 2019, 11, 2432. [CrossRef]

25. Migliaccio, M.; Gambardella, A. Microwave radiometer spatial resolution enhancement. IEEE Trans. Geosci. Remote Sens. 2006, 43, 1159-1169. [CrossRef]

26. Shutko, A.M.; Krapivin, V.F.; Haarbrink, R.B.; Sidorov, I.A.; Novichikhin, E.P.; Archer, F.; Krisilov, A.D. Practical Microwave Radiometric Risk Assessment; Professor Marin Drinov Academic Publishing House: Sofia, Bulgaria, 2010; 88p.

27. Kurihara, J.; Takahashi, Y.; Sakamoto, Y.; Kuwahara, T.; Yoshida, K. HPT: A high spatial resolution multispectral sensor for microsatellite remote sensing. Sensors 2018, 18, 619. [CrossRef]

28. Pampalony, P. Microwave radiometry of forests. Waves Rand. Med. 2004, 14, S275-S298. [CrossRef]

29. Haarbrink, R.; Krapivin, V.F.; Krisilov, A.; Krisilov, V.; Novichikhin, E.P.; Shutko, A.M.; Sidorov, I. Intelligent Data Processing in Global Monitoring and Security; ITHEA: Melbourne, Australia; Sofia-Kiev: Kyiv, Ukraine, 2011; 410p.

30. Bosisio, A.V.; Dechambre, M. Predictions of microwave attenuation through vegetation: A comparison with measurements. Int. J. Remote Sens. 2004, 25, 3973-3997. [CrossRef]

31. Valendik, E.N. Basic principles of boreal forest fire protection in Eurasia. In Proceedings of the 20th Tall Timbers Fire Ecology Conference: Fire in Ecosystem Management: Shifting the Paradigm from Suppression to Prescription, Boise, Idaho, 7-10 May 1996; Tall Timbers Research Station: Tallahassee, FL, USA, 1998; pp. 398-402. 
32. Chuvieco, E.; Cocero, D.; Riaño, D.; Martin, P.; Martínez-Vegac, J.; de la Rivad, J.; Pérez, F. Combining NDVI and surface temperature for the estimation of live fuel moisture content in forest fire danger rating. Remote Sens. Environ. 2004, 92, 322-331. [CrossRef]

33. Krapivin, V.F.; Varotsos, C.A.; Marechek, S.V. The dependence of the soil microwave attenuation on frequency and water content in different types of vegetation: An empirical model. Water Air Soil Pollut. 2018, 110, 229. [CrossRef]

34. Bonafoni, S.; Alimenti, F.; Angelucci, G.; Tasselli, G. Microwave radiometry imaging for forest fire detection: A simulation study. Progress Electrom. Res. 2011, 112, 77-92. [CrossRef]

35. Milshin, A.A.; Grankov, A.G. Some experimental results of microwave emission of forest in L-band. Inv. Earth Space 2000, 3, 50-57. (In Russian)

36. Sukov, A.I.; Soldatov, V.Y.; Krapivin, V.F.; Cracknell, A.P.; Varotsos, C.A. A sequential analysis method for the prediction of tropical hurricanes. Int. J. Remote Sens. 2008, 29, 2787-2798. [CrossRef]

37. González-Alonso, F.; Merino-De-Miguel, S.; Roldán-Zamarrón, A.; García-Gigorro, S.; Cuevas, J.M. Forest biomass estimation through NDVI composites. The role of remotely sensed data to assess Spanish forests as carbon sinks. Int. J. Remote Sens. 2006, 27, 5409-5415. [CrossRef]

38. Krapivin, V.F.; Varotsos, C.A.; Soldatov, V.Y. New Ecoinformatics Tools in Environmental Science: Applications and Decision-Making; Springer: London, UK, 2015; 903p. [CrossRef]

39. Sun, G.; Domec, J.-C.; Amatya, D.M. Forest evapotranspiration: Measurement and modelling at multiple scales. In Forest Hydrology: Processes, Management and Assessment; Amatya, D.M., Williams, T.M., Bren, L., de Long, C., Eds.; CABI Publishers: London, UK, 2016; Chapter 3pp. 32-50.

40. Onuchin, A.; Burenina, T.; Pavlov, I. Hydrological consequences of timber harvesting in landscape zones of Siberia. Environments 2017, 4, 51.

41. Pengxin, W.; Shaomin, L.; Jindi, W. Study of NDVI-T's space by combining LAI and evaporation. Sci. China Series D Earth Sci. 2006, 49, 747-754.

42. Cracknell, A.P.; Varotsos, C.A. Editorial and cover: Fifty years after the first artificial satellite: From Sputnik 1 to Envisat. Int. J. Remote Sens. 2007, 28, 2071-2072. [CrossRef]

43. Kondratyev, K.Y.; Krapivin, V.F. Monitoring and prediction of natural disasters. Nuov. Ciment. C Geophys. Space Phys. C 2004, 27, 657-672.

44. Schunk, C.; Ruth, B.; Leuchner, M.; Wastl, C.; Menzel, A. Comparison of different methods for the in situ measurement of forest litter moisture content. Nat. Hazards Earth Syst. Sci. 2016, 16, 403-415. [CrossRef]

45. Chen, S.; Wen, Z.; Jiang, H.; Zhao, Q.; Xiuying Zhang, X.; Chen, Y. Temperature Vegetation Dryness Index Estimation of Soil Moisture under Different Tree Species. Sustainability 2015, 7, 11401-11407. [CrossRef]

46. Sharples, J.J.; McRae, R.H.D.; Weber, R.O.; Gill, A.M. A simple index for assessing fire danger rating. Environ. Model. Softw. 2009, 24, 764-774. [CrossRef]

47. Torngern, P.; Oren, R.; Palmroth, S.; Novitck, K. Water balance of pine forests: Synthesis of new and published results. Agric. Forest Meteorol. 2018, 259, 107-117. [CrossRef]

48. Speich, M.J.R.; Zappa, M.; Lischke, H. Sensitivity of forest water balance and physiological drought predictions to soil and vegetation parameters: A model-based study. Environ. Model. Softw. 2018, 102, 213-232. [CrossRef]

49. Gorbatenko, V.; Dulzon, A. Variations of thunderstorm. In Proceedings of the 5th Korea-Russia International Symposium on Science and Technology, Tomsk, Russia, 26 June-3 July 2001; Institute of Electrical and Electronics Engineers: Piscataway, NJ, USA, 2001; Volume 2, pp. 62-66.

50. Konstantinova, D.A.; Gorbatenko, V.P.; Polyakov, D.V. Spatial distribution of the thunderstorm activity characteristics for the territory of western Siberia. In Proceedings of the 23 rd International Symposium on Atmospheric and Ocean Optics: Atmospheric Physics, Irkutsk, Russia, 30 November 2017; Matvienko, G.G., Romanovskij, S.R., Eds.; Institute of Atmospheric Optics: Irkutsk, Russia, 2018; Volume 10466. [CrossRef]

51. Mullayarov, V.A.; Toropov, A.A.; Kozlov, V.I. Patterns of spatial distribution of positive thunderstorm discharges in Eastern Siberia. Russ. Meteor. Hydrol. 2009, 34, 364-370. [CrossRef]

52. Tarabukina, L.; Kononova, N.; Kozlov, V.; Innokentiev, D. Analysis of atmospheric circulation condition during severe thunderstorms in Yakutia in 2009-2016. In E3S Web of Conferences; EDP Sciences: Les Uis, France, 2018; Volume 62, p. 01001. [CrossRef]

53. Kamatsu, H.; Kumagai, T.; Hotta, N. Effects of vertical air temperature distribution within forest canopies on photosynthesis and transpiration. Bull. Kyushu University Forum 2007, 88, 1-19. 
54. Baranovskiy, N.V.; Kuznetsov, G.V. Forest Fire Occurrences and Ecological Impact Prediction; Publishing House of the Siberian Branch of the Russian Academy of Sciences: Novosibirsk, Russia, 2017; 259p.

55. Prestemon, J.P.; Butry, D.T. Time to burn: Modeling wildland arson as an autoregressive crime function. Am. J. Agric. Econ. 2005, 87, 756-770. [CrossRef]

56. Shamina, O.; Kiseleva, M. It is conflagrated what is profitable to cut down. How work "commercial" the forest arsons? Russian BBC News, 2 August 2019.

57. Krapivin, V.F.; Shutko, A.M.; Chukhlantsev, A.A.; Golovachev, S.P.; Phillips, G.W. GIMS-based method for vegetation microwave monitoring. Environ. Model. Softw. 2006, 21, 330-345. [CrossRef]

58. Chukhlantsev, A.A. Microwave Radiometry of Vegetation Canopies; Springer: Berlin, Germany, 2006; 287p.

59. Meesters, A.G.C.A.; De Jeu, R.A.M.; Manfred, O. Analytical derivation of the vegetation optical depth from the microwave polarization difference index. IEEE Geosci. Remote Sens. Let. 2005, 2, 121-123. [CrossRef]

60. Wen, J.; Jackson, T.J.; Bindlish, R.; Hsu, A.Y. Retrieval of soil moisture and vegetation water content using SSM/I data over a corn and soybean region. J. Hydromet. Spec. Sect. 2005, 6, 854-863. [CrossRef]

61. Singh, R.P.; Dadhwal, V.K. Comparison of space-based microwave polarization difference index and normalized difference vegetation index for crop growth monitoring. Indian J. Radio Space Phys. 2003, 32, 193-197.

62. Ershov, D.V.; Kovganko, K.A., Shuliak. Present possibilities of geoinformation monitoring system GIS-ISRM of Rosleshoz. Fire Saf. J. 2010, 19, 38-46. (In Russian)

63. Basilevich, N.I. Biological Productivity of the Ecosystem of Northern EuroAsia; Science Publication: Moscow, Russia, 1993; 293p. (In Russian)

64. Krestov, P. Forest vegetation of Easternmost Russia (Russian Far East). In Forest Vegetation of Northeast Asia; Kolbek, J., Strutek, M., Box, E., Eds.; Springer: London, UK, 2003; pp. 93-180.

65. Kolesnik, S.; Kolmakov, A.; Tsyupa, I. Thunderstorm activity in the West Siberian Region and its influence on the electromagnetic hum of the ELF band. In Proceedings of the Russian Open Conference on Radio Wave Propagation (RWP), Kazan, Russia, 1-6 July 2019. [CrossRef]

66. Lee, H.; College, D.B.; Mcculley, R.L.; Archer, S.R. Soil moisture and soil-litter mixing effects on surface litter decomposition: A controlled environment assessment. Soil Biol. Biochem. 2014, 72, 123-132. [CrossRef]

67. Felde, G.W. The effect of soil moisture on the $37 \mathrm{GHz}$ microwave polarization difference index (MPDI). Int. J. Remote Sens. 1998, 19, 1055-1078. [CrossRef]

68. Kondratyev, K.Y.; Krapivin, V.F.; Savinykh, V.P.; Varotsos, C.A. Global Ecodynamics: A Multidimensional Analysis; Springer/PRAXIS: Chichester, UK, 2004; 658p.

69. Kempka, T.; Kaiser, T.; Solbach, K. Microwaves in fire detection. Fire Saf. J. 2006, 41, 327-333. [CrossRef]

70. Varotsos, C. An introduction to our chaotic atmosphere and climate. Phys. Today 2020, 73, 54. [CrossRef]

71. Efstathiou, M.N.; Varotsos, C.A. On the altitude dependence of the temperature scaling behaviour at the global troposphere. Int. J. Remote Sens. 2010, 31, 343-349. [CrossRef]

72. Varotsos, C.A.; Efstathiou, M.N.; Cracknell, A.P. On the scaling effect in global surface air temperature anomalies. Atmos. Chem. Phys. 2013, 13, 5243-5253. [CrossRef]

73. Varotsos, C.; Cartalis, C. Re-evaluation of surface ozone over Athens, Greece, for the period 1901-1940. Atmos. Res. 1991, 26, 303-310. [CrossRef]

74. Cracknell, A.P.; Varotsos, C.A. New aspects of global climate-dynamics research and remote sensing. Int. J. Remote Sens. 2011, 32, 579-600. [CrossRef]

75. Efstathiou, M.N.; Varotsos, C.A. Intrinsic properties of Sahel precipitation anomalies and rainfall. Theor. Appl. Clim. 2012, 109, 627-633. [CrossRef]

76. Tzanis, C.; Tsivola, E.; Efstathiou, M.; Varotsos, C. Forest fires pollution impact on the solar UV irradiance at the ground. Fresenius Environ. Bull 2009, 18, e2158.

77. Varotsos, C.; Efstathiou, M.; Tzanis, C. Scaling behaviour of the global tropopause. Atmos. Chem. Phys. 2009, 9, 677-683. [CrossRef]

(C) 2020 by the authors. Licensee MDPI, Basel, Switzerland. This article is an open access article distributed under the terms and conditions of the Creative Commons Attribution (CC BY) license (http://creativecommons.org/licenses/by/4.0/). 